\title{
Maternal Care in Free-Ranging Arboreal Grey-Cheeked Mangabeys (Lophocebus albigena johnstoni) in Kibale National Park, Uganda
}

\author{
Małgorzata Arlet ${ }^{a} \quad$ Linda-Liisa Veromann-Jürgenson $^{b} \quad$ Lynne Isbell $^{c}$ \\ Raivo Mänd $^{d}$ Alban Lemasson $^{\mathrm{e}}$ \\ a Department of Human Evolutionary Biology, Institute of Anthropology, Adam Mickiewicz \\ University in Poznań, Poznań, Poland; b Estonian University of Life Sciences, Tartu, Estonia; \\ 'Department of Anthropology and Animal Behaviour Graduate Group, University of \\ California, Davis, CA, USA; ${ }^{d}$ Department of Zoology, Institute of Ecology and Earth Sciences, \\ University of Tartu, Tartu, Estonia; ${ }^{\mathrm{E}}$ Ethologie animale et humaine, CNRS, Université de \\ Rennes, Université de Caen Normandie, Paimpont, France
}

\section{Keywords}

Maternal behaviour - Maternal experience $\cdot$ Parity $\cdot$ Infant sex $\cdot$ Infant age

\begin{abstract}
Maternal styles have been intensively studied in a variety of terrestrial species of primates, but far less in arboreal species. However, to have a balanced view of the evolution of maternal care, it is necessary to investigate this behaviour in the context of habitat. Here, we investigate whether the mother's parity, age and dominance rank, as well as the infant's age and sex, influence maternal care and mother-infant proximity in arboreal grey-cheeked mangabeys (Lophocebus albigena). We observed 13 mother-infant dyads in four free-ranging groups for 6 months. Our main finding is that maternal care is a dynamic process affected by a mix of mothers' and infants' characteristics. We found that first-time mothers spent more time watching their infants than multiparous mothers, who carried, groomed and protected their infants more often. We also found that low-ranking mothers prevented their infants from leaving them more often than did high-ranking mothers. Moreover, mothers adjusted their care as infants became older. They groomed and protected female infants more than male infants, behaviours common in female-bonded species. Our study shows the ever-changing dynamics of maternal care related to infant age and highlights the role of the mother's parity and rank in this process.

(c) 2019 S. Karger AG, Basel
\end{abstract}

\section{KARGER}

(c) 2019 S. Karger AG, Basel

E-Mail karger@karger.com www.karger.com/fpr 


\section{Introduction}

Primates have a relatively long infant developmental stage compared to other mammals of similar size [Strier, 2007] and therefore need more parental care than other mammals for individuals to become independent [Harvey and Clutton-Brock, 1985]. In most species of non-human primates, only the females take care of infants, with some exceptions, e.g., marmosets (Callithrix spp.) and tamarins (Saguinus spp.) where males help by carrying infants [Maestripieri, 2011].

Maternal style is the consistent application of particular forms of maternal care by individual females toward multiple infants over time [Berman, 1990]. Maternal styles are often categorized into three types: (1) rejecting mothers that frequently interrupt contact with their infants and stay away from them for a long time; (2) protective mothers that tend to maintain visual contact and spatial proximity with their infants, and (3) laissez-faire mothers that allow their infants to stay close by while also not keeping them from moving away [Hinde, 1974; Rosenblum and Youngstein, 1974; Altmann, 1980; Fairbanks, 1996; Bardi and Huffman, 2002].

The quality of maternal care is influenced by several factors, including the mother's experience in raising offspring, her age and her dominance rank. Experience appears to be a very important factor [Abello and Colell, 2006]. A comparative analysis found that in 15 of 21 studies of primates, infants of younger or primiparous (firsttime) mothers had lower survival rates than those of older mothers [Pusey, 2012]. Primiparous mothers are more likely to mistreat or abandon their first infant, resulting in infant death [Schino and Troisi, 2005; Arlet et al., 2014]. For example, in a study of Japanese macaques (Macaca fuscata), $40 \%$ of infants born to primiparous mothers aged 4, 5 and 6 years or older were abandoned at birth [Schino and Troisi, 2005]. With subsequent births, maternal neglect declines and the quality of maternal care increases [Maestripieri and Carroll, 1998]. Lack of experience may also elevate stress for primiparous mothers, increasing the likelihood that offspring will not thrive emotionally and/or physically [Martin, 2013].

In an earlier study of grey-cheeked mangabeys (Lophocebus albigena), we found that infants of older mothers had higher survival rates than those born to younger, first-time mothers [Arlet et al., 2014]. We suggested that this could be related to the mother's age but also to experience. In other species, such as green monkeys (Chlorocebus sabaeus), infants of primiparous mothers with allomothering experience (taking care of others' infants), survived better than those of primiparous mothers without such experience [Fairbanks, 1990]. However, there may be some age-related influences on maternal care that are independent of experience. For example, young mothers are still growing [Bercovitch et al., 1998; Setchell et al., 2002] and may face a greater trade-off between foraging for food and taking care of the infant [Setchell et al., 2002]. Moreover, their smaller body size will make carrying their growing offspring more energetically costly [Altmann and Samuels, 1992]. Finally, the quality or quantity of milk they produce may be poorer than that of older (and typically multiparous) mothers, which could affect suckling frequencies [Hinde et al., 2009; Martin, 2013].

Social position may influence maternal behaviour as well by, for example, the extent of aggression directed toward the mother and her infant. In Japanese macaques, low-ranking mothers receive twice as much aggression as high-ranking mothers and are therefore more prone to abandoning their infants, which may be linked to female 
stress [Schino and Troisi, 2005]. Infants of lower-ranking mothers are also likely to experience aggression more often than infants of higher-ranking mothers, which may translate into more protective mothering [Smuts and Smuts, 1993].

The mother's dominance rank may also interact with characteristics of the infant to affect the quality of maternal care. For example, in vervet monkeys (Chlorocebus pygerythrus), high-ranking mothers rejected daughters more often than sons, whereas low-ranking mothers did not [Lee, 1984]. A study of yellow baboons (Papio cynocephalus) showed that high-ranking mothers carried daughters more often than sons whereas low-ranking mothers showed no such sex bias [Altmann and Samuels, 1992]. In the same study, high-ranking mothers also tended to carry infants of both sexes for less time than low-ranking mothers [Altmann and Samuels, 1992]. In rhesus macaques (Macaca mulatta), mothers prevented female infants from leaving more so than male infants [Mitchell, 1968]. Besides infant sex, numerous studies show that infant age has an important influence on the maternal care. For example, younger infants receive more care than older infants [Altmann, 1980; Goldizen, 1987; Altmann and Samuels, 1992; Onishi and Nakamichi, 2011].

Most studies of maternal style in cercopithecine primates have been conducted on terrestrial or semi-terrestrial species, e.g., green monkeys [Fairbanks and McGuire, 1988], yellow baboons [Altmann 1980] and rhesus macaques [Berman, 1990], which may have more flexibility than committed arboreal cercopithecines (e.g., blue monkeys Cercopithecus mitis, red-tailed monkeys Cercopithecinus ascanius) where the risk of falling is higher for their infants [Nakamura and Ramadhani, 2014]. With the risk of injury and death from falls greater and the visibility more limited [Nishida et al., 2003], it seems likely that the arboreal environment poses somewhat different challenges than the terrestrial environment for mothers and infants [Förster and Cords, 2002]. Thus, we might expect mothers in arboreal species to be more restrictive toward their infants with regard to leaving the mother or travelling alone. However, there has been comparatively little research on maternal care in arboreal species [Förster and Cords, 2002] to determine whether arboreal cercopithecines, like terrestrial cercopithecines, have multiple maternal styles or must be generally more restrictive because of the limitations of the arboreal habitat. In a study of long-tailed macaques, (M. fascicularis), mothers and their infants of 10-20 weeks of age were generally in contact with each other a greater proportion of the time at higher levels in the canopy than at lower levels, suggesting that the risk of falling might contribute to maternal care [Karssemeijer et al., 1990]. In contrast, in arboreal blue monkeys, infants gained spatial independence earlier in life than more terrestrial cercopithecine species, such as patas monkeys (Erythrocebus patas), rhesus and long-tailed macaques and yellow baboons [Nicolson, 1987; Förster and Cords, 2003, 2005]. Perhaps greater precociality is important in the arboreal environment, or alternatively, at least in guenons, it may be related to lower rates of agonism normally expressed within groups [Förster and Cords, 2005].

Here, we present the first detailed study on maternal behaviour in free-ranging grey-cheeked mangabeys. We investigated the effects of the mother's parity, age and dominance rank, as well as the infant's sex and age, on maternal care and on motherinfant proximity. Grey-cheeked mangabeys are closely related to baboons [Harris and Disotell, 1998; Burrell et al., 2009] and, like baboons, they live in multi-male, multifemale groups in which females are the philopatric sex and have stable, linear dominance hierarchies [Chancellor and Isbell, 2009]. However, group sizes are typically

Maternal Care in Free-Ranging Arboreal Grey-Cheeked Mangabeys
Folia Primatol 2019;90:441-455 DOI: $10.1159 / 000499656$ 
Table 1. Composition of grey-cheeked mangabey study groups in Kibale National Park, Uganda

\begin{tabular}{lcccc}
\hline & BT1 & LC1 & LC2 & MK \\
\hline Group size & $17-23$ & $19-26$ & $13-16$ & $10-15$ \\
Adult females & 7 & 7 & $4-5$ & 4 \\
Adult males & $2-6$ & $3-8$ & $1-2$ & $3-4$ \\
Subadult females & $0-1$ & $0-2$ & $0-1$ & $0-2$ \\
Subadult males & 1 & 0 & 1 & 0 \\
Juvenile females & $1-2$ & 0 & 1 & $0-2$ \\
Juvenile males & 2 & 5 & 3 & 1 \\
Infant females & 1 & 2 & 0 & 2 \\
Infant males & 3 & 2 & 3 & 0 \\
\hline
\end{tabular}

The values are presented as minimum and maximum of the number of individuals per agesex class over the study period.

smaller [Waser, 1977; Henzi and Barrett, 2003], and most of their time is spent arboreally. As locomotor and feeding substrate influences a large range of behaviours [Clutton-Brock and Harvey, 1977], we have no reason to expect that the same is not true for maternal care. It seems likely that the highly diverse, visually dense and 3-dimensional environment of arboreal species is a challenge for maternal care and protection.

Because parity influences maternal care in many species, we expected to find that multiparous (experienced) mothers provide better maternal care than primiparous mothers. We also expected the age of the mother, as it tends to be connected with experience, to have an impact on the quality of maternal care. Since the social organization of grey-cheeked mangabeys is similar to that of other papionin species, we expected to find rank effects on maternal care, with high-ranking females spending more time with infants. We also expected differential care of male and female infants, with mothers protecting their daughters more frequently than sons. We also expected mothers to devote more attention and care to younger infants. Finally, since mangabeys are an arboreal species, we expected greater time in direct contact between mothers and infants, i.e., more time spent carrying infants, in comparison to more terrestrial species. As most maternal care studies have been carried out in terrestrial cercopithecine species, our study helps to fill a gap and brings attention to maternal care in less well-known arboreal species.

\section{Methods}

\section{Study Area and Subjects}

The study site, Kibale National Park, Uganda, is a $795-\mathrm{km}^{2}$ moist, evergreen, medium-altitude forest with areas of swampland, grassland, thicket and colonizing forest [Chapman and Lambert, 2000]. We collected data from the end of July 2011 to March 2012 on four groups of grey-cheeked mangabeys: Lower Camp 1 (LC1), Lower Camp 2 (LC2), Butanzi 1 (BT1), and Mikana (MK), which ranged in size from 10 to 26 individuals (1-8 adult males, 4-7 adult females, and 0-3 infants; Table 1) [Janmaat et al., 2009]. 
Table 2. Mothers' and infants' characteristics

\begin{tabular}{|c|c|c|c|c|c|}
\hline $\begin{array}{l}\text { Group/ } \\
\text { female }\end{array}$ & $\begin{array}{l}\text { Age, } \\
\text { years }\end{array}$ & Rank & Parity & $\begin{array}{l}\text { Infant } \\
\text { age, months }\end{array}$ & $\begin{array}{l}\text { Infant } \\
\text { sex }\end{array}$ \\
\hline \multicolumn{6}{|l|}{ BT1 } \\
\hline Kagezi & 8 & 2 & $\mathrm{PP}$ & 0.5 & $\mathrm{~m}$ \\
\hline Kadogo & 10 & 3 & MP & 0.5 & $\mathrm{f}$ \\
\hline Mwirima & 7 & 4 & MP & 4.0 & $\mathrm{~m}$ \\
\hline Muhimbo & 7 & 7 & $\mathrm{PP}$ & 5.0 & $\mathrm{~m}$ \\
\hline \multicolumn{6}{|l|}{$\mathrm{LC} 1$} \\
\hline Nyakato & 14 & 1 & MP & 9.0 & $\mathrm{~m}$ \\
\hline Ngonzi & 9 & 5 & MP & 4.0 & $\mathrm{f}$ \\
\hline Namara & 11 & 6 & MP & 4.0 & $\mathrm{f}$ \\
\hline Kaisiki & 9 & 7 & MP & 4.0 & $\mathrm{~m}$ \\
\hline \multicolumn{6}{|l|}{$\mathrm{LC} 2$} \\
\hline Kiiki2 & 13 & 1 & MP & 9.0 & $\mathrm{~m}$ \\
\hline Kissa2 & 8 & 2 & $\mathrm{PP}$ & 10.0 & $\mathrm{~m}$ \\
\hline Tindereya & 12 & 4 & MP & 5.0 & $\mathrm{~m}$ \\
\hline \multicolumn{6}{|l|}{ MK } \\
\hline Kakende & 12 & 1 & MP & 0.5 & $\mathrm{f}$ \\
\hline Broom & 8 & 2 & $\mathrm{PP}$ & 0.5 & $\mathrm{f}$ \\
\hline
\end{tabular}

Age of females is given in years and age of infants in months (at the end of the study). Age of the females older than 10 years was estimated. Parity: PP, primiparous females (first-time mothers); MP, multiparous females (experienced mothers). Infant sex: $\mathrm{m}$, male; $\mathrm{f}$, female.

We have monitored these groups monthly since 1999, with continuous observation since 2004 (LC1, BT1, MK) or 2010 (LC2) up to 2014. All animals were habituated and individually recognized [Arlet et al., 2014]. We identified females using natural markings such as relative body size, nipple colour and size, and tail characteristics (scars, shape and thickness of hair [Strum and Western, 1982]. In our study, we recorded the behaviour of all females with infants $(n=13)$, and we knew the birth dates of their infants. In our study, we included 8 male and 5 female infants (Table 2). Most infants are weaned between 6 and 7 months [Veromann, 2011]. Grey-cheeked mangabey females mature between 5 and 6.2 years, and they have their first births between 6.8 and 7.8 years [Deputte, 1992; Arlet et al., 2014, 2015]. Our 13 adult female subjects, all with infants, were characterised as either primiparous or multiparous based on their known histories (Table 2).

Female dominance ranks were based on Arlet et al. [2014] using 91 agonistic interactions from the 2011-2012 study period. We recorded all dyadic agonistic interactions per group, including non-physical threats (e.g., facial displays), approach-avoids (i.e., moving away from another who is approaching), supplants (i.e., taking the place of another), physical contacts (e.g., biting, tail-pulling and pushing), and chases (i.e., aggressively pursuing another). We constructed dominance matrices for each study group, with rank order determined by minimizing the number of reversals against the hierarchy (i.e., interactions below the diagonal). The ranks of our subjects were stable during the 6-month study as no changes were found when comparing the first half of the study with the second half.

\section{Behavioural Observations}

Two authors (M.E.A. and L.-L.V.-J.) and field assistant Richard Kaseregenyu (R.K.) collected data from July 2011 until March 2012 (M.E.A. and L.-L.V.-J. July-September 2011, R.K. September-December 2011 and M.E.A. January-March 2012). Observers were trained by the same person and collected behavioural data simultaneously on the same females' behaviour to 
Table 3. Description of maternal behaviours in grey-cheeked mangabeys (modified from Patterson, 2001)

\begin{tabular}{ll}
\hline Behaviour & Description \\
\hline Watch infant & Female observes infant \\
Hold infant & Female cradles infant while sitting \\
Carry infant & Female transports infant \\
Groom infant & Female uses her mouth and hands to pick through infant's fur \\
Protect infant & Female prevents group member from touching or taking her infant \\
Restrict infant from leaving & Female keeps her infant from leaving \\
Restrict infant from contact & Female keeps her infant from contact with group members \\
Restrict infant from suckling & Female keeps her infant from taking her nipple into its mouth \\
\hline
\end{tabular}

test for interobserver reliability (Spearman test: $r_{s}=0.87, p<0.001, n=620$ ). We carried out the observations as a rotation between groups - we followed one group for 6 days every 5 weeks [Arlet et al., 2009]. We opportunistically determined the focal sampling order in each group by first sighting of an adult female that had not yet been sampled during that particular round, while taking care to balance morning and afternoon sampling. We collected $247 \mathrm{~h}$ of focal observations, with a mean \pm SD of $17.6 \pm 13.9$ h per female.

We focal-sampled each female with an infant for 90 min per day (excluding time out of sight) for a total of 6 days over 6 months. During that time, we recorded behaviours designated as "watch," "hold," "carry" and "groom." For analyses, we used occurrences of these behaviours and quantified them as rates per unit time. We also recorded all occurrences of behaviours designated as "protect," "restrict leaving mother's proximity," "restrict contact with others" and "restrict suckling" and quantified them for analyses as rates per unit time. We provide operational definitions in Table 3. We estimated proximity between mothers and infants (in metres) every time the behaviour changed, and every time the distance between the mother and infant changed. All observers were trained to estimate focal female distances to the infant and we found a high degree of reliability between observers' estimates (Spearman test: $r_{s}=0.9, p<0.01, n=370$ ).

\section{Statistical Analysis}

We used generalized linear mixed models with identity link function to examine predictors of the expression of maternal behaviours. We considered models with the following predictors as main effects: mothers' parity (primiparous vs. multiparous), age (in years), dominance rank (1, 2 , 3, etc.; estimated for all females in each group), infant age (in months) and infant sex. We included group and infant identity as random factors. In our model, the dependent variable was the number of each behaviour recorded per month of observation (i.e., per month of infant age) divided by monthly observation time in minutes (to counterbalance the differences in sampling effort and to acknowledge developmental changes over time). The ranks and ages of the mothers and the ages of their infants were both fixed factors and were considered continuous factors, whereas parity and infant sex were categorical factors.

We used generalized linear mixed models with identity link function to test the influence of mothers' parity, age, dominance rank, and infant age and sex on mother-driven proximity to infants. We considered group and infant identity as random factors. Here, the dependent variable was average proximity of the infant from the mother per month, calculated from every instance the distance between the mother and infant changed. As above, the dependent variable was the number of each behaviour recorded per month of observation, mother's rank and age and infant's age were continuous factors, and parity and infant sex were categorical factors.

The study design, with repeated observations of each female in a group over the observation period, calls for statistical models that incorporate several factors (of maternal care). Our data meet the assumptions of normality of generalized linear mixed models. We used STATISTICA 10 (StatSoft Inc., USA) for all the analyses with a significance threshold set at 0.05 . 


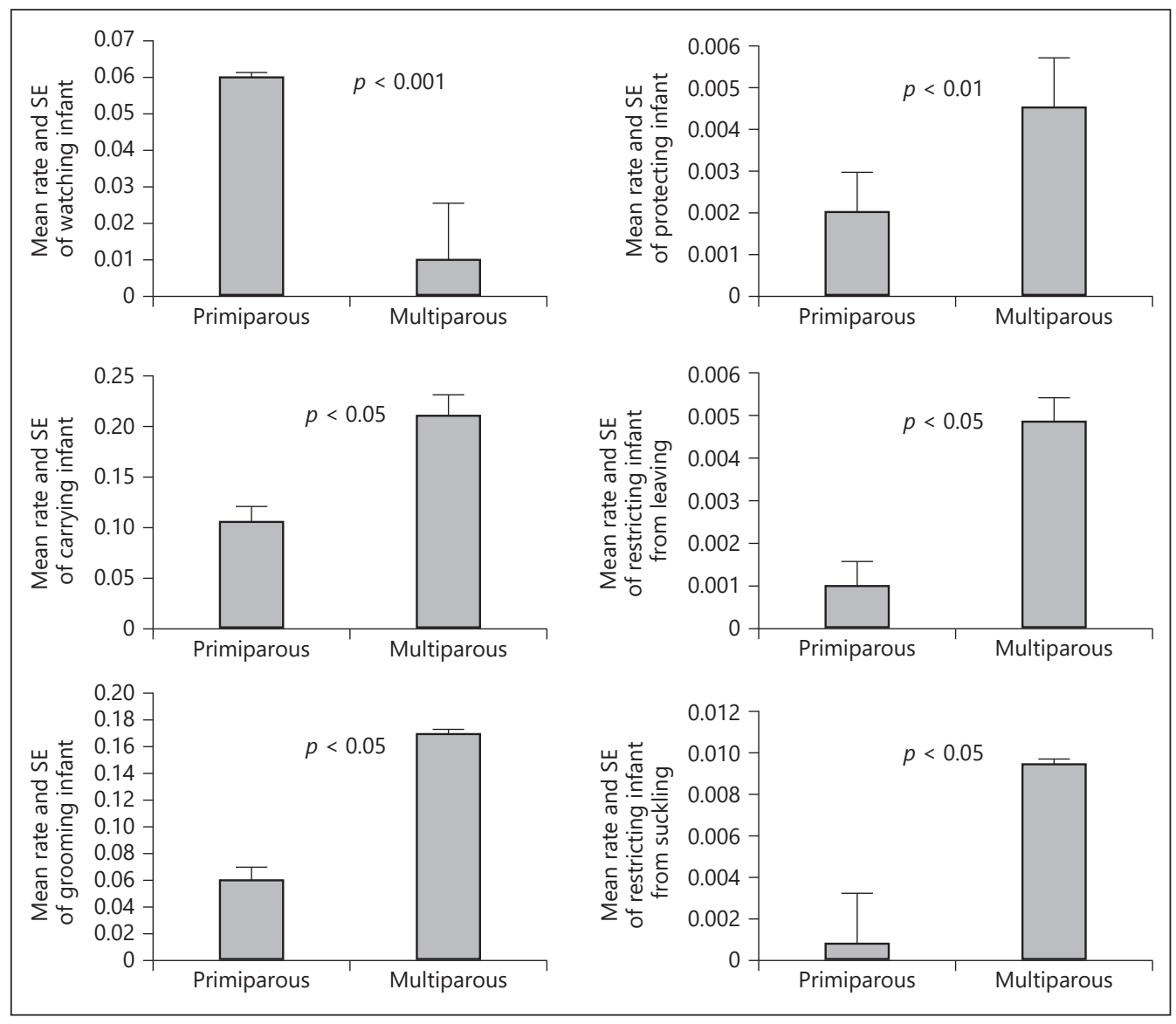

Fig. 1. Relation between mother's rearing experience and the rate of maternal behaviours. The number of observations represents the mean number of observations per female per minute. Error bars are standard errors.

\section{Results}

\section{Influence of Mother's Parity, Rank and Age on Maternal Behaviours}

We found that mother's parity, but not age or rank, influenced most forms of maternal care. Primiparous mothers watched their infants longer than did multiparous mothers (primiparous: mean $\pm \mathrm{SD}=0.06 \pm 0.004 \mathrm{~min}$; multiparous: mean \pm $\mathrm{SD}=0.01 \pm 0.0005 \mathrm{~min}$ ) but multiparous mothers carried (primiparous: mean \pm $\mathrm{SD}=0.09 \pm 0.02 / \mathrm{min}$; multiparous: mean $\pm \mathrm{SD}=0.17 \pm 0.005 / \mathrm{min})$ and groomed (primiparous: mean $\pm \mathrm{SD}=0.06 \pm 0.002 / \mathrm{min}$; multiparous: mean $\pm \mathrm{SD}=0.17 \pm$ $0.0005 / \mathrm{min}$ ) their infants more often, and were more protective than primiparous mothers (primiparous: mean $\pm \mathrm{SD}=0.002 \pm 0.0006 / \mathrm{min}$; multiparous: mean $\pm \mathrm{SD}=$ $0.004 \pm 0.0006 / \mathrm{min} ; p<0.05$ in all cases; Table 4, Fig. 1). Multiparous mothers restricted their infants from leaving (primiparous: mean $\pm S D=0.001 \pm 0.003 / \mathrm{min}$; multiparous: mean $\pm \mathrm{SD}=0.004 \pm 0.009 / \mathrm{min}$ ) and from suckling (primiparous: mean 


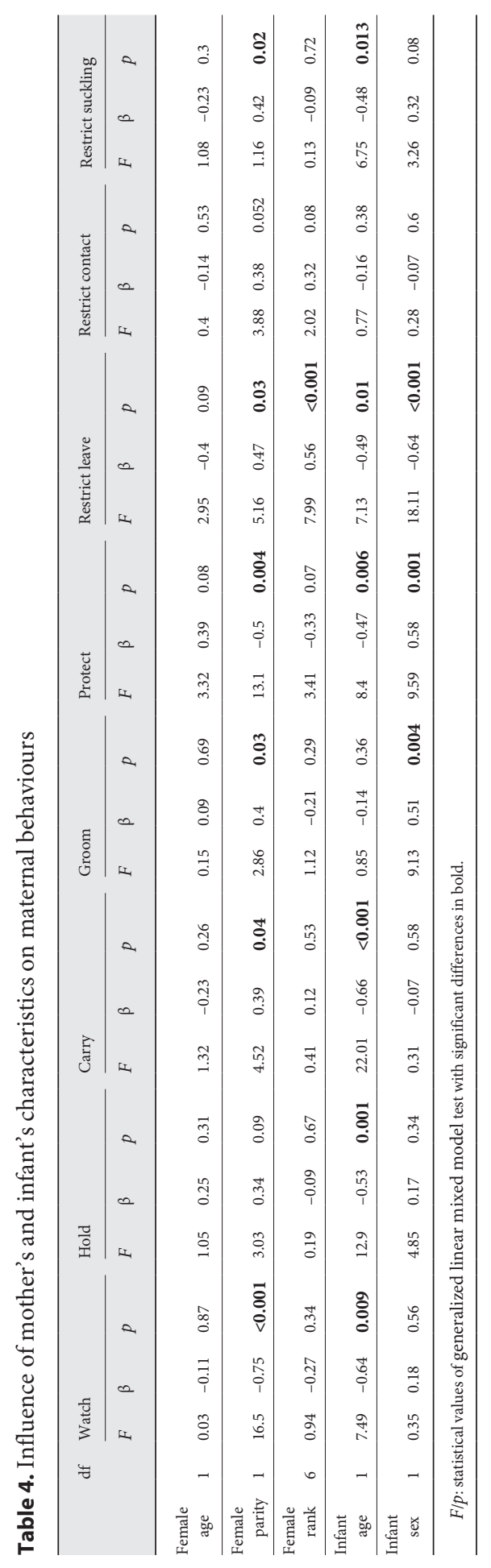




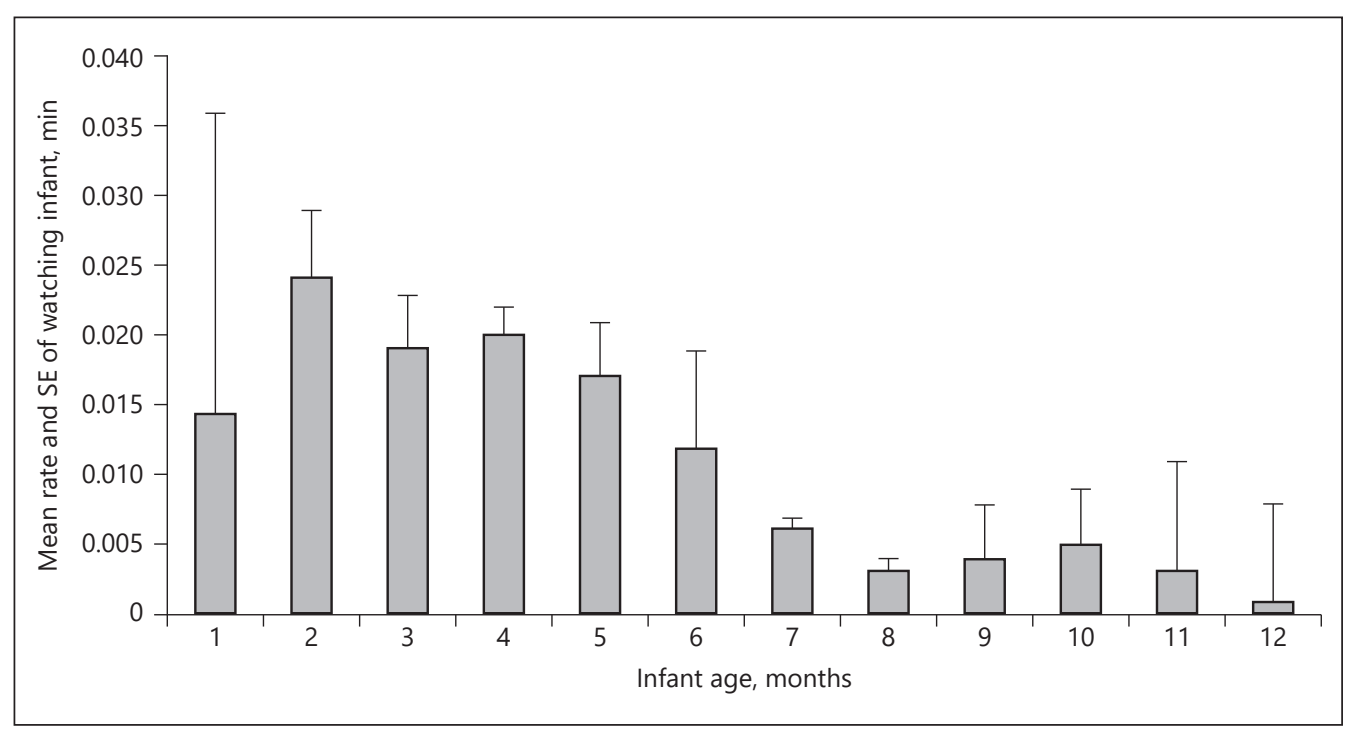

Fig. 2. Relation between age of infants and the time mothers spent watching them. The number of observations represents the monthly number of observations per minute. Error bars are standard errors.

$\pm \mathrm{SD}=0.0007 \pm 0.002 / \mathrm{min}$; multiparous: mean $\pm \mathrm{SD}=0.009 \pm 0.002 / \mathrm{min})$ more often than primiparous mothers. All mothers displayed comparable holding (primiparous: mean $\pm S D=0.06 \pm 0.07 / \mathrm{min}$; multiparous: mean $\pm S D=0.1 \pm 0.13 / \mathrm{min}$ ) and restricting from contact regardless of their maternal experience (primiparous: mean $\pm \mathrm{SD}=$ $0.003 \pm 0.005 / \mathrm{min}$; multiparous: mean $\pm \mathrm{SD}=0.01 \pm 0.01 / \mathrm{min} ; p>0.05)$. Restricting infants from leaving was correlated with dominance rank, as low-ranking mothers (rank: 5-7) restricted their infants more than higher-ranking mothers (rank 1-4: mean $\pm \mathrm{SD}=0.001 \pm 0.003 / \mathrm{min}$; rank 5-7: mean $\pm \mathrm{SD}=0.012 \pm 0.018 / \mathrm{min}$; Spearman correlation: $r=0.53, p<0.05)$. Mother's age had no effect on any measure.

\section{Influence of Infant's Age and Sex on Maternal Behaviours}

In our study, most measures of maternal care were affected by the age of the infant (Table 4). Mothers with 3-month-old infants spent, on average, $36 \%$ of their time carrying those infants whereas mothers with 6-month-old infants spent, on average, $15 \%$ of their time carrying them. The younger the infant was, the longer its mother spent watching it (1-3 months: mean $\pm \mathrm{SD}=0.02 \pm 0.002 / \mathrm{min}$; $4-6$ months: mean $\pm \mathrm{SD}=0.01 \pm$ $0.001 / \mathrm{min} ;>6$ months: mean $\pm \mathrm{SD}=0.005 \pm 0.004 / \mathrm{min}$; Fig. 2$)$, holding it $(1-3$ months: mean $\pm \mathrm{SD}=0.17 \pm 0.09 / \mathrm{min}$; $4-6$ months: mean $\pm \mathrm{SD}=0.04 \pm 0.07 / \mathrm{min} ;>6$ months: mean $\pm \mathrm{SD}=0.0 \pm 0.0 / \mathrm{min})$ and carrying it $(1-3$ months: mean $\pm \mathrm{SD}=0.34 \pm 0.2 / \mathrm{min}$; 4-6 months: mean $\pm \mathrm{SD}=0.15 \pm 0.1 / \mathrm{min} ;>6$ months: mean $\pm \mathrm{SD}=0.02 \pm 0.05 / \mathrm{min})$.

Younger infants were also more protected than older ones (1-3 months: mean \pm $\mathrm{SD}=0.006 \pm 0.002 / \mathrm{min} ; 4-6$ months: mean $\pm \mathrm{SD}=0.003 \pm 0.005 / \mathrm{min} ;>6$ months: mean $\pm \mathrm{SD}=0.0 \pm 0.0 / \mathrm{min}$; Fig. 3 ); most cases of protection (71\%) were observed with infants younger than 4 months. We did not observe protection of infants older 


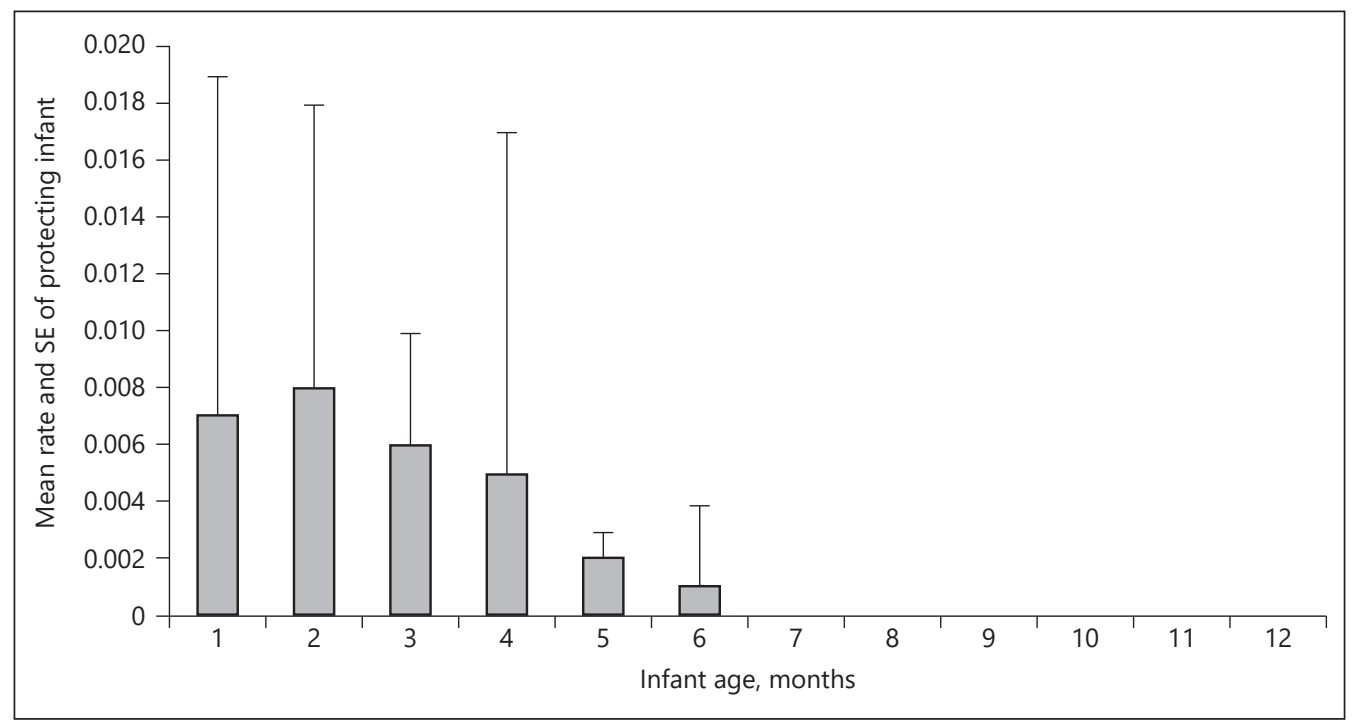

Fig. 3. Relation between age of infants and the time mothers spent protecting them. The number of observations represents the monthly number of observations per minute. Error bars are standard errors.

Table 5. Influence of mother's and infant's characteristics on mother-infant distance

\begin{tabular}{lccc}
\hline & df & $F$ & $p$ \\
\hline Female age & 1 & 1.44 & 0.24 \\
Female parity & 1 & 2.03 & 0.16 \\
Female rank & 1 & 2.61 & 0.11 \\
Infant age & 1 & 87.8 & $<0.001$ \\
Infant sex & 1 & 1.79 & 0.19 \\
\hline
\end{tabular}

$F / p$ : statistical values of generalized linear mixed model test.

than 7 months. Mothers restricted younger infants from leaving more often than older infants $(1-3$ months: mean $\pm \mathrm{SD}=0.008 \pm 0.01 / \mathrm{min} ; 4-6$ months: mean \pm $\mathrm{SD}=0.002 \pm 0.004 / \mathrm{min} ;>6$ months: mean $\pm \mathrm{SD}=0.0008 \pm 0.002 / \mathrm{min})$. Older infants were restricted more often than younger infants from suckling (1-3 months: mean \pm $\mathrm{SD}=0.00 \pm 0.00 / \mathrm{min} ; 4-6$ months: mean $\pm \mathrm{SD}=0.001 \pm 0.003 / \mathrm{min} ;>6$ months: mean $\pm \mathrm{SD}=0.17 \pm 0.27 / \mathrm{min})$.

Mothers groomed female infants more often than they groomed male infants (daughters: mean $\pm S D=0.09 \pm 0.012 / \mathrm{min}$; sons: mean $\pm \mathrm{SD}=0.016 \pm 0.02 / \mathrm{min}$ ) and protected infant females more often than infant males (daughters: mean $\pm \mathrm{SD}=0.008$ $\pm 0.01 / \mathrm{min}$; sons: mean $\pm \mathrm{SD}=0.001 \pm 0.005 / \mathrm{min})$. Infant females were restricted from leaving more often than infant males (daughters: mean $\pm \mathrm{SD}=0.007 \pm 0.01 / \mathrm{min}$; sons: mean $\pm \mathrm{SD}=0.003 \pm 0.008 / \mathrm{min})$. 
Influence of Mothers' and Infants' Characteristics on Mother-Infant Proximity

We found that mother-infant proximity was influenced only by infant age (Table 5). As might be expected, distances between mothers and infants increased with age as infants were moving away from mothers and increasingly interacting with other group members (Spearman correlation: $r=0.88, p<0.05$ ). At $1-3$ months, the mean distance \pm SD between mothers and infants was $1.9 \pm 0.85 \mathrm{~m}$, at 4-6 months, it was $4.9 \pm 0.77 \mathrm{~m}$, and at $>6$ months, it was $8.7 \pm 1.67 \mathrm{~m}$.

\section{Discussion}

The study of maternal behaviour in cercopithecine primates is largely restricted to species that spend much of their time on the ground. Because of the greater risk of injury from falling from trees, cercopithecine species that are arboreal may express maternal behaviour somewhat differently, especially to keep infants from moving independently.

Our study is the first to investigate maternal behaviour in grey-cheeked mangabeys, an arboreal cercopithecine primate species. We found that, as with many other species, the mother's parity strongly influenced maternal care in that multiparous mothers carried, groomed, protected their infants, and prevented their infants from leaving, more often than primiparous mothers. Therefore, the difference in the quality of maternal care between primiparous and multiparous mothers may be directly related to their acquired experience with infants, possibly even of losing them in the past. Our study showed that multiparous mothers carried their infants twice as much as primiparous mothers did.

Differences between primiparous and multiparous mothers in maternal behaviour may help to explain the lower survival rates of infants of primiparous mothers in this population [Arlet et al., 2014]. Nearly 25\% of infant deaths during a 9-year study occurred because infants fell from trees during bouts of fighting between males [Arlet et al., 2014]. Our study showed that grey-cheeked mangabey mothers with 3-monthold infants carried them for more time (36\%) than has been reported for the terrestrial yellow baboons (25\%) [Altmann and Samuels, 1992], which could be a response to the infant's high risk of falling at this young age. However, mangabeys and yellow baboons were similar in how much time they carried older, 6-month-old infants (mangabeys: 15\%, baboons: 16\%) [Altmann and Samuels, 1992]. In the arboreal environment in which grey-cheeked mangabeys live, it might be particularly beneficial for mothers to be attentive to their very young infants, but it may take primiparous mothers time to learn that. Here we found that multiparous mothers carried their infants twice as much as primiparous mothers did. In our study we found that parity had an effect on maternal care, as is found in terrestrial species. Therefore, we can expect that other, more universal types of experience or age-related factors also affect offspring survival in grey-cheeked mangabeys, e.g., the tendency to neglect infants by primiparous mothers [Maestripieri and Carroll, 1998; Schino and Troisi, 2005). However, we found that primiparous females watched their infants more than experienced mothers, which may be related to attraction towards "novelty," in this case an infant, as watching behaviour itself was not connected with protective behaviour, carrying or holding by first-time mothers. We detected the effect of mother's rank only on restricting infants from leaving, with low-ranking females restricting their infants from leav-

Maternal Care in Free-Ranging Arboreal Grey-Cheeked Mangabeys
Folia Primatol 2019;90:441-455 DOI: $10.1159 / 000499656$
451 
ing more often than high-ranking females. For species with frequent rank-related agonism, greater restrictiveness from leaving by low-ranking mothers is to be expected. For example, in rhesus macaques, lower-ranking mothers were more restrictive and less willing to allow their infant to be approached by others [Maestripieri, 2005]. This difference may have a stronger phylogenetic than substrate signal. For instance, the rate of agonism between female grey-cheeked mangabeys is similar to that of Japanese macaques and lower than that of chacma baboons [Chancellor and Isbell, 2009], both of which spend more time on the ground than mangabeys but are, along with mangabeys, papionins. In contrast, the rate of agonism between female mangabeys is higher than that of both terrestrial patas monkeys and arboreal blue monkeys, which are cercopithecins [Chancellor and Isbell, 2009]. As the rate of agonism between highand low-ranking female grey-cheeked mangabeys varied between 12 and 64\% (of all agonistic interactions between females) and depended on the group [Arlet, unpubl. observation], restricting infants from leaving may be related to female-female aggression in some groups but may also be influenced by increased aggression (and stress) within the group when migrating males were present [Arlet et al., 2007, 2008, 2013].

The age of the infant was an important factor influencing the dynamic of maternal care. Not surprisingly, as infants became older, all measured maternal behaviours decreased except for grooming. Mother-infant distances also increased. Similarly, in captive rhesus macaques, cradling, retrieving and restraining were inversely correlated with infant age [Seay, 1966]. Younger infants appear to be at greater risk of being accidentally harmed than older infants, and when taken from the mother, they may become malnourished and dehydrated [Maestripieri, 1994]. When the infant is older and less dependent on its mother, it may be safer for the mother to allow others to handle her infant, which then frees her to feed more efficiently and reduce travel costs [Förster and Cords, 2005].

Finally, we found that female infants were groomed longer, protected more often and were prevented from leaving more often than were sons. In our previous study we found that male infants have higher mortality than female infants [Arlet et al., 2014], and our present findings may help to explain why. There are at least two nonexclusive explanations for this sex bias in maternal care. As a proximate explanation, more frequent grooming and greater protection of daughters may be a consequence of infant temperament. For instance, in squirrel monkeys (Saimiri sciureus), rhesus macaques and patas monkeys, male infants play more than female infants [Biben, 1986; Rowell and Chism, 1986; Brown and Dixson, 2000]. As an ultimate explanation, sex bias in maternal grooming, protecting and preventing infants from leaving may be the result of selection on mothers and daughters to become more bonded than mothers and sons. Like other cercopithecine primates, female grey-cheeked mangabeys typically stay in their natal groups for life, and they form the social core of the groups whereas males emigrate when they reach sexual maturity [Olupot and Waser, 2001, 2005]. In species with female-philopatric groups, when mortality is higher for infant males than females and maternal investment is biased toward females [e.g., Maestripieri, 2001], it might be expected that mothers will also behave in other ways that promote infant female survival.

In summary, variation in the maternal behaviours we measured could be attributed to factors related to arboreal life to some degree (e.g., because primiparous mothers were less experienced, they may have been less protective than multiparous mothers by carrying their infants less, which could lead to falls and increased infant mortal- 
ity), but they also reflect the mother's parity independent of arboreality, her rank and the infant's age and sex. Thus, maternal care in grey-cheeked mangabeys generally resembles that of the more terrestrial papionin primates. As most primates spend at least some of their time in trees, mothers must balance keeping infants safe from falls with allowing them the mobility to gain experience for navigating arboreal pathways. This challenge may be accentuated in highly arboreal species such as grey-cheeked mangabeys. As mothers gain experience, they may learn to better balance restrictiveness and permissiveness, while at the same time, as infants grow older and more competent, it may be less costly for mothers to relinquish some of their control. Whether there is enough variation in maternal care in grey-cheeked mangabeys that individuals can be classified as rejecting mothers, protective mothers or laissez-faire mothers will require long-term observations as primiparous mothers become multiparous.

\section{Acknowledgments}

We thank the Uganda Wildlife Authority, Uganda National Council for Science and Technology and personnel at the Makerere University Biological Field Station in Kanyawara for permission to work in Kibale National Park. We thank Richard Kaseregenyu for his invaluable assistance in the field and two anonymous reviewers for their constructive comments and suggestions.

\section{Statement of Ethics}

All data were collected from habituated, wild animals without interfering with their activities. The research complied with the laws of Uganda, and the protocols were approved by the Uganda Wildlife Authority and Uganda National Council for Science and Technology at the time the field research was conducted.

\section{Disclosure Statement}

The authors confirm that there are no conflicts of interest involved in publishing this work.

\section{Funding Sources}

This research was supported by the "Mobilitas" postdoctoral grant (MJD56 to M.A.), by the Estonian Research Council (institutional grant IUT34-8 to R.M.), and A.L. was supported by the Institut Universitaire de France.

\section{Author Contributions}

All authors made substantial contributions to this paper. L.-L.V.-J. and M.A. collected data, M.A. analysed data and drafted the article, L.I., R.M. and A.L. revised it critically for important intellectual content. All authors gave final approval of the submitted version and have no competing interests. 


\section{References}

Abello MT, Colell M (2006). Analysis of factors that affect maternal behaviour and breeding success in great apes in captivity. International Zoo Yearbook 40: 323-340.

Altmann J (1980). Baboon Mothers and Infants. Cambridge, Harvard University Press.

Altmann J, Samuels A (1992). Costs of maternal care: infant-carrying in baboons. Behavioural Ecology and Sociobiology 29: 391-398.

Arlet ME, Carey JR, Molleman F (2009). Species age and sex differences in type and frequencies of injuries and impairments among four arboreal primate species in Kibale National Park Uganda. Primates 50: 65-73.

Arlet ME, Isbell LA, Kaasik A, Molleman F, Chancellor RL, Chapman CA, Mänd R, Carey JR (2015). Determinants of reproductive performance among female grey-cheeked mangabeys (Lophocebus albigena) in Kibale National Park, Uganda. International Journal of Primatology 36: 55-73.

Arlet ME, Isbell LA, Molleman F, Kaasik A, Chancellor RL, Chapman CA, Mänd R, Carey JR (2014). Maternal investment and infant survival in grey-cheeked mangabeys (Lophocebus albigena). International Journal of Primatology 35: 476-490.

Arlet ME, Molleman F, Chapman CA (2007). Indications for female mate choice in grey-cheeked mangabeys Lophocebus albigena johnstoni in Kibale National Park, Uganda. Acta Ethologica 10: 89-95.

Arlet ME, Molleman F, Chapman CA (2008). Mating tactics in male grey-cheeked mangabeys (Lophocebus albigena). Ethology 114: 841-852.

Arlet ME, Molleman F, Isbell LA, Chancellor RL, Carey JR, Mänd R (2013). Correlations between social context and fecal glucocorticoid metabolite concentrations in free-ranging female grey-cheeked mangabeys (Lophocebus albigena) in Kibale National Park, Uganda. Folia Biologica 61: 239-246.

Bardi M, Huffman MA (2002). Effects of maternal style on infant behaviour in Japanese macaques ( $M a-$ caca fuscata). Developmental Psychology 41: 364-372.

Bercovitch FB, Lebron MR, Martinez HS, Kessler MJ (1998). Primigravidity, body weight and costs of rearing first offspring in rhesus macaques. American Journal of Primatology 46: 135-144.

Berman CM (1990). Consistency in maternal behaviour within families of free-ranging rhesus monkeys: an extension of the concept of maternal style. American Journal of Primatology 22: 159-169.

Biben M (1986). Individual and sex-related strategies of wrestling play in captive squirrel monkeys. Ethology 71: 229-241.

Brown GR, Dixson AF (2000). The development of behavioural sex differences in infant rhesus macaques (Macaca mulatta). Primates 41: 63-77.

Burrell AS, Jolly CJ, Tosi AJ, Disotell TR (2009). Mitochondrial evidence for the hybrid origin of the kipunji Rungwecebus kipunji Primates: Papionini. Molecular Phylogeny Evolution 51: 340-348.

Chancellor RL, Isbell LA (2009). Food site residence time and female competitive relationships in wild grey-cheeked mangabeys (Lophocebus albigena). Behavioural Ecology and Sociobiology 63: 14471458.

Chapman CA, Lambert JE (2000). Habitat alteration and the conservation of African primates: a case study of Kibale National Park Uganda. American Journal of Primatology 50: 169-186.

Clutton-Brock TH, Harvey PH (1977). Primate ecology and social organization. Journal of Zoology, London 183: 1-39.

Deputte BL (1992). Life history of captive grey-cheeked mangabeys: physical and sexual development. International Journal of Primatology 13: 509-531.

Fairbanks LA (1990). Reciprocal benefits of allomothering for female vervet monkeys. Animal Behaviour 40: 553-562.

Fairbanks LA (1996). Individual differences in maternal styles: causes and consequences for mothers and offspring. Advanced Study of Behaviour 25: 579-611.

Fairbanks LA, McGuire MT (1988). Long-term effects of early mothering behaviour on responsiveness to the environment in vervet monkeys. Developmental Psychology 21: 711-724.

Förster S, Cords M (2002). Development of mother-infant relationships and infant behaviour in wild blue monkeys Cercopithecus mitis stuhlmanni. In The Guenons: Diversity and Adaptation in African Monkeys (Glenn ME, Cords M, eds.), pp 245-272. New York, Plenum-Kluwer.

Förster S, Cords M (2003). Arboreality and infant behavioural development: new data from wild blue monkeys. American Journal of Physical Anthropology 36: 95-96.

Förster S, Cords M (2005). Socialization of infant blue monkeys Cercopithecus mitis stuhlmanni: allomaternal interactions and sex differences. Behaviour 142: 869-896.

Goldizen A (1987). Tamarins and marmosets: communal care of offspring. In Primate Societies (Smuts B, Cheney DL, Seyfarth RM, Wrangham RW, Struhsaker TT, eds.), pp 4-43. Chicago, University of Chicago Press.

Harris EE, Disotell TR (1998). Nuclear gene trees and the phylogenetic relationships of the mangabeys (Primates: Papionini). Molecular Biology and Evolution 15: 892-900.

Harvey PH, Clutton-Brock TH (1985). Life history variation in primates. Evolution 39: 559-581.

Folia Primatol 2019;90:441-455

DOI: $10.1159 / 000499656$
Arlet/Veromann-Jürgenson/Isbell/Mänd/

Lemasson 
Henzi SP, Barrett L (2003). Evolutionary ecology, sexual conflict, and behavioural differentiation among baboon populations. Evolutionary Anthropolology 12: 217-230.

Hinde R (1974). Biological Bases of Human Social Behaviour. New York, McGraw-Hill.

Hinde K, Power ML, Oftedal OT (2009). Rhesus macaque milk: magnitude, sources, and consequences of individual variation over lactation. American Journal of Physical Anthropology 138: 148-157.

Janmaat KR, Olupot W, Chancellor RL, Arlet ME, Waser PM (2009). Long-term site fidelity and individual home range shifts in grey-cheeked mangabeys. International Journal of Primatology 30: 443466.

Karssemeijer GJ, Vos DR, van Hooff JARAM (1990). The effect of some non-social factors on motherinfant contact in long-tailed macaques Macaca fascicularis. Behaviour 113: 272-291.

Lee PC (1984). Early infant development and maternal care in free-ranging vervet monkeys. Primates 25 : 36-47.

Maestripieri D (1994). Social structure, infant handling, and mothering styles in group-living Old World monkeys. International Journal of Primatology 15: 531-553.

Maestripieri D (2001). Female-biased maternal investment in rhesus macaques. Folia Primatologica 72 : 44-47.

Maestripieri D (2005). Primate Psychology. Cambridge, Harvard University Press.

Maestripieri D (2011). Emotion, stress, and maternal motivation in primates. American Journal of Primatology 73: 516-529.

Maestripieri D, Carroll KA (1998). Risk factors for infant abuse and neglect in group-living rhesus monkeys. Psychological Science 9: 143-145.

Martin RD (2013). How We Do It: The Evolution and Future of Human Reproduction. New York, Basic Books.

Mitchell GD (1968). Attachment differences in male and female infant monkeys. Child Development 39: 611-620.

Nakamura M, Ramadhani A (2014). Hidden risk of arboreality? An arboreal death of an infant chimpanzee at Mahale. Pan African News 21: 17-19.

Nicolson NA (1987). Infants, mothers, and other females. In Primate Societies (Smuts BB, Cheney DL, Seyfarth RM, Wrangham RW, Struhsaker TT, eds.), pp 330-342. Chicago, University of Chicago Press.

Nishida T, Corp N, Hamai M, Hasegawa T, Hiraiwa-Hasegawa M, Hosaka K, Hunt KD, Itoh N, Kawanaka K, Matsumoto-Oda A, Mitani JC, Nakamura M, Norikoshi K, Sakamaki T, Turner L, Uehara S, Zamma K (2003). Demography, female life history, and reproductive profiles among the chimpanzees of Mahale. American Journal of Primatology 59: 99-121.

Olupot W, Waser PM (2001). Correlates of intergroup transfer in male grey-cheeked mangabeys. International Journal of Primatology 19: 169-187.

Olupot W, Waser PM (2005). Patterns of male residency and intergroup transfer in grey-cheeked mangabeys (Lophocebus albigena). American Journal of Primatology 66: 331-349.

Onishi K, Nakamichi M (2011). Maternal infant monitoring in a group of free-ranging Japanese macaques Macaca fuscata. International Journal of Primatology 32: 209-222.

Pusey AE (2012). Magnitude and sources of variation in female reproductive performance. In The Evolution of Primate Societies (Mitani JC, Call J, Kappeler PM, Palombit RA, Silk JB, eds.), pp 143-166. Chicago, University of Chicago Press.

Rosenblum LA, Youngstein KP (1974). Developmental changes in compensatory dyadic response in mother and infant monkeys. In The Effects of the Infant on Its Caregiver (Lewis M, Rosenblum LA, eds.), pp 141-161. New York, Wiley \& Sons.

Rowell TE, Chism J (1986). The ontogeny of sex differences in the behaviour of patas monkeys. International Journal of Primatology 7: 83-107.

Schino G, Troisi A (2005). Neonatal abandonment in Japanese macaques. American Journal of Physical Anthropology 126: 447-452.

Seay B (1966). Maternal behaviour in primiparous and multiparous rhesus monkeys. Folia Primatologica 4: 146-168.

Setchell JM, Lee PC, Wickings EJ, Dixson AF (2002). Reproductive parameters and maternal investment in mandrills Mandrillus sphinx. International Journal of Primatology 23: 51-68.

Smuts BB, Smuts RW (1993). Male aggression and sexual coercion of females in nonhuman primates and other mammals: evidence and theoretical implications. Advanced Study of Behaviour 22: 1-63.

Strier K (2007). Primate Behavioural Ecology, 3rd ed. Boston, Allyn \& Bacon.

Strum SC, Western JD (1982). Variation in fecundity with age and environment in olive baboons Papio anubis. American Journal of Physical Anthropology 3: 61-76.

Veromann LL (2011). Maternal Care in Grey-Cheeked Mangabeys. Master's thesis, University of Tartu.

Waser PM (1977). Feeding ranging and group size in the mangabey Cercocebus albigena. In Primate Ecology (Clutton-Brock TH, ed.), pp 183-222. London, Academic Press.

Maternal Care in Free-Ranging Arboreal

Grey-Cheeked Mangabeys
Folia Primatol 2019;90:441-455

DOI: $10.1159 / 000499656$ 